\title{
Genetic Diversity Assessment of Acid Lime (Citrus aurantifolia Swingle) Landraces in Nepal, Using SSR Markers
}

\author{
Ram Lal Shrestha ${ }^{1 *}$, Durga Datta Dhakal ${ }^{2}$, Durga Mani Gautum², Krishna Prasad Paudyal ${ }^{3}$, \\ Sangita Shrestha ${ }^{4}$ \\ ${ }^{1}$ Agricultural Research Station (ARS), Dhankuta, Nepal; ${ }^{2}$ Institute of Agriculture and Animal Science (IAAS), Chitwan, Nepal; \\ ${ }^{3}$ Horticulture Research Division (HRD), Lalitpur, Nepal; ${ }^{4}$ Nepal Academy of Science and Technology (NAST), Lalitpur, Nepal. \\ Email: ${ }^{*}$ rals_135@yahoo.com
}

Received September $26^{\text {th }}, 2012$; revised October $20^{\text {th }}, 2012$; accepted November $25^{\text {th }}, 2012$

\begin{abstract}
Acid lime (Citrus aurantifolia) is an important commercial fruits crop, cultivated in terai to high hills of Nepal. High variation of acid lime fruits are observed in existing landraces due to crossing within the other citrus species. Determination of genetic variation is important to the plant breeders for development of high yielding variety and hybrids. Therefore, an attempt has been made to study the genetic diversity of 62 acid lime landraces, collected from different altitudinal range in the eastern part of Nepal, using SSR markers. Twelve Simple Sequence Repeat (SSR) primer pairs were used to assess the genetic diversity of acid lime. The average genetic similarity level among the 62 accessions was 0.77 , ranging from 0.54 to 1.0 and separated five major cluster groups. Total of 33 alleles were detected by eleven primer pairs and size of alleles ranged from 50 to 225. Average polymorphic information content (PIC) value was 0.50 , whereas highest 0.75 and lowest 0.18 was observed in CAT01 and GT03 loci respectively. The results of the study clearly indicated that, SSR markers are highly polymorphic and more informative for the assessment of genetic diversity of acid lime landraces.
\end{abstract}

Keywords: Alleles; Genetic Diversity; Polymorphic; SSR Markers

\section{Introduction}

Acid lime (Citrus aurantifolia Swingle) belongs to the family Rutaceae and sub family Aurantiodae. It is one of the important commercial fruits, which has been cultivated in 60 out of 75 districts of Nepal from $125 \mathrm{~m}$ to $1800 \mathrm{~m}$ altitude range [1]. Production and productivity of acid lime in Nepal is low, 8.4 ton per ha [2], as compared to other countries like Argentina, 19 ton per ha and India, 12.2 ton per ha [3]. Low productivity is due to the limitation of high yielding variety. It is cross pollinated crop. Production and quality of fruits are decreasing every year due to inbreeding depression, which may be the results of crossing within the Citrus species. High level of genetic erosion was observed in acid lime landraces, with narrow genetic base [4]. In this context, study of genetic diversity and conservation of genetic resources is urgent for breeding and variety development program. Acid lime fruit is an important source of vitamin " $C$ " for human nutrition. It has high medicinal values and used for the prevention of various diseases like bones and joints, piles,

"Corresponding author. dysentery, cold, influenza, constipation and scurvy [5].

Normally citrus plants are diploid, with chromosome number $2 \mathrm{n}=18$. Flowers are cross pollinated produced natural hybrid. Bud mutation also occurs, leading to different morphological characters in different branches of the same plant. So it has more scope of wide chromosomal diversity within same species [6] for variety development program. Limes hybridize freely with other Citrus species, like lime and lemon, lime and kumquat and developed many hybrids [7], or a tri-hybrid cross of citron, pummelo and Microcitrus [8]. In addition to the key lime, there is Tahiti or Persian lime $(2 n=3 x=27)$, presumably a hybrid of lime and citron. The Tahiti lime is hardier and widely adopted in the subtropics; in SouthEast Asia.

Nepal is the home land of citrus species because of wide availability and cultivation of wild citrus species [9], but limited work has been carried out on evaluation and characterization of genetic materials. Assessment of genetic diversity within the acid lime landraces is the basis for breeding, conservation of genetic resources and 
variety development work. The estimation technique of genetic diversity in the plant species is different. Traditionally, evaluation of germplasm has been carried out on the basis of morphological traits [10]. In recent years, a number of Polymerase Chain Reaction (PCR) based and DNA based molecular marker technology have been developed for the effective quantification of genetic variation and cultivar identity [11].

Molecular markers such as isozymes, Restriction Fragment Length Polymorphism (RFLP) and Randomly Amplified Polymorphic DNA (RAPD) has been used to study the genetic diversity, taxonomy, cultivar identification [12-14] and the construction of genetic linkage maps $[15,16]$ in various Citrus species. During the last decade, microsatellite or simple sequence repeats (SSR) has been commonly used for genetic mapping [17] and genetic diversity study [18]. It is regarded to be a more reliable marker than the others, because they are highly polymorphic and usually co-dominant [19-21], easy to use, evenly distribution in the genome, transferable between laboratories and not influenced by environmental condition [22]. Microsatellites are short sequence elements composed of tandem repeat units, 1 - 6 base pairs (bp) in length [23]. These repeat sequences have shown to be highly polymorphic within species and applied in population genetics [24], and genome mapping [25]. It has been used in the genetic diversity studies of many plant species, such as Citrus [26], apple [27], grape [28], tomato [29], peanut [30], tea [31] and Litchi [32]. In citrus and related genera, microsatellite has been used for phylogenetic studies [33] assessment of genetic variability [34] and identification of zygotic plant [35]. This study was carried out on existing acid lime orchards at different altitudinal range in the eastern part of Nepal. The main objective of this study is, to determine the genetic diversity of acid lime landraces and select highly variable genotypes for breeding and variety development purpose, using SSR marker.

\section{Materials and Methods}

\subsection{Plant Material}

A total of 62 young expanding healthy leaf samples (6 - 8 weeks) were collected for DNA extraction from the farmer's orchards of eastern Nepal. Samples were collected randomly, from the selected trees of three agro ecological domains representing terai, mid-hills and high-hills (Table 1) and kept in silica gel. They were brought to Nepal Academy of Science and Technology (NAST), Khumal-

Table 1. Altitudinal range, accessions number and locality details of sample collection sites of acid lime landraces.

\begin{tabular}{|c|c|c|c|c|c|c|c|c|}
\hline \multicolumn{3}{|c|}{ Above $1200 \mathrm{~m}$ asl } & \multicolumn{3}{|c|}{$600-1200 \mathrm{~m}$ asl } & \multicolumn{3}{|c|}{ Less than $600 \mathrm{~m}$ asl } \\
\hline Acc No & Altitude (M) & VDC-Ward No. & Acc No. & Altitude (M) & VDC-Ward No. & Acc No. & Altitude (M) & VDC-Ward No. \\
\hline LT-1 & 1605 & Okhre-8 & LD-49 & 1185 & Bodhe-1 & LM-43 & 135 & Sunpur-2 \\
\hline $\mathrm{LT}-17$ & 1750 & Fachmara-7 & LKv-60 & 1185 & Balara-1 & LM-44 & 135 & Sunpur-2 \\
\hline LT-18 & 1710 & Fachmara-9 & LKm-61 & 1185 & Balara-1 & LM-45 & 135 & Sunpur-2 \\
\hline LT-15 & 1655 & Fachmara-9 & LKr-62 & 1185 & Balara-1 & LM-58 & 135 & Sunpur-2 \\
\hline LD-50 & 1638 & Rajarani-9 & LD-48 & 1181 & Bodhe-1 & LS-34 & 128 & Narsing-2 \\
\hline LT-8 & 1505 & Okhre-8 & LD-25 & 1180 & Balara-1 & LS-35 & 128 & Narsing-4 \\
\hline LT-22 & 1505 & Sudap-1 & LD-26 & 1175 & Balara-1 & LS-36 & 128 & Narsing-4 \\
\hline LT-9 & 1500 & Okhre-5 & LD-27 & 1175 & Balara-1 & LS-37 & 128 & Narsing-4 \\
\hline LT-21 & 1485 & Fachamara-1 & LD-28 & 1175 & Balara-1 & LS-38 & 128 & Narsing-4 \\
\hline LT-20 & 1410 & Fachamara-8 & LD-29 & 1175 & Balara-1 & LS-39 & 128 & Narsing-4 \\
\hline LT-16 & 1405 & Fachamara-7 & LD-30 & 1175 & Balara-1 & LS-40 & 128 & Narsing-4 \\
\hline LT-19 & 1350 & Fachamara-7 & LD-59 & 1175 & Balara-1 & LS-41 & 128 & Narsing-4 \\
\hline LT-13 & 1315 & Fachamara-7 & LT-4 & 1155 & Okhre-1 & LS-42 & 128 & Narsing-4 \\
\hline LT-12 & 1310 & Fachamara-7 & LT-5 & 1155 & Okhre-3 & LS-56 & 128 & Narsing-4 \\
\hline LT-14 & 1308 & Fachamara-7 & LT-6 & 1150 & Okhre-3 & LS-57 & 128 & Narsing-4 \\
\hline LT-23 & 1308 & Sudap-7 & LD-31 & 1150 & Dhnk-3 & LM-51 & 125 & Pathari-2 \\
\hline LT-3 & 1305 & Okhre-8 & LT-7 & 1145 & Okhre-2 & LM-52 & 125 & Pathari-2 \\
\hline LD-24 & 1290 & Balehara-8 & LT-10 & 1135 & Okhre-3 & LM-53 & 125 & Pathari-2 \\
\hline LT-2 & 1285 & Okhre-1 & LT-11 & 1130 & Okhre-3 & LM-54 & 125 & Pathari-2 \\
\hline LD-46 & 1278 & Bodhe-2 & LD-32 & 1130 & Balhra-3 & LM-55 & 125 & Pathari-2 \\
\hline LD-47 & 1278 & Bodhe-2 & LD-33 & 1130 & Balhra-1 & - & - & - \\
\hline
\end{tabular}

Note: $\mathrm{LT}=$ Lime Terhathum, $\mathrm{LD}=$ Lime Dhankuta, $\mathrm{LM}=$ Lime Morang, $\mathrm{LS}=$ Lime Sunsari, LKm = Lime Madrasi, LKr $=$ Lime Rampur, LKv = Lime Banarasi, $\mathrm{VDC}=$ Village Development Committee, $\mathrm{m}=$ meter, asl $=$ above sea level. 
tar laboratory for molecular study.

\subsection{DNA Isolation}

Leaf samples $(100 \mathrm{mg})$ were ground to a fine powder in liquid nitrogen. DNA was extracted by using DNeasy extraction mini-kit (QIAGEN, www//qiagen.com) procedures. The extracted DNA $(200 \mu \mathrm{l})$ was stored at $-20^{\circ} \mathrm{C}$ until use. The quality and quantity of DNA were determined by Bio-photometer (Eppendorf Company, Germany).

\subsection{SSR-PCR Optimization}

A total of twelve published SSR primer pairs for citrus species were used in the present study [36-38]. These primers were selected based on Polymorphic Information Content (PIC) values (Table 2). PCR amplification was performed in BIOER Thermal cycler (Bioer Technology Co. Ltd., China Version 2001.1.0). The PCR reactions were performed in total volume $25 \mu \mathrm{l}$, containing 0.2 $\mathrm{mM}$ dNTPs, $2.5 \mathrm{mM} \mathrm{MgCl} 2,2.5 \mu \mathrm{l}$ of $10 \times$ Taq buffer [100 mM Tris- $\mathrm{HCl}, \mathrm{pH} 8.8$ at $25^{\circ} \mathrm{C}, 500 \mathrm{mM} \mathrm{KCl} 0.8 \%$ (v/v), Nonidet P40]; 0.6 U Taq DNA polymerase (Fermentas, Life science; $5 \mathrm{u} / \mu \mathrm{l}), 0.8 \mathrm{pmol}$ of each primer (Eurofins Genomic Test Pvt Ltd., Banglor, India) and 0.8 ng of template DNA. The PCR program consisted of initial denaturation at $94^{\circ} \mathrm{C}$ for $5 \mathrm{~min} ; 32$ cycles of $94^{\circ} \mathrm{C}$ for 1 minute; followed by annealing at $60^{\circ} \mathrm{C}$ for $30 \mathrm{sec}$; extension at $72^{\circ} \mathrm{C}$ for $1 \mathrm{~min}$ and final elongation at $72^{\circ} \mathrm{C}$ for 4 minute. The PCR products were separated on 3\% agarose gel (Embi Tec. San Diego, CA) and stained with Ethidium bromide (10 mg/mL Promegha) for 35 minute and de-stained in distilled water for 15 minutes. The DNA fragments were photographed and documented using Gel doc system (Syngene UK). Electrophoresis was conducted in $1 \times$ TAE buffer (Tris, acetic acid and EDTA buffer) at 100 volt for 45 minutes $(9.0 \mathrm{~V} / \mathrm{cm})$.

Table 2. Nucleotide sequence, repeat motifs, number of alleles, allele size range and polymorphic information content (PIC) value of 11 SSR primers pairs.

\begin{tabular}{|c|c|c|c|c|c|c|}
\hline S No & Locus & Sequence $\left(5^{\prime}-3^{\prime}\right)$ and $\left(3^{\prime}-5^{\prime}\right)$ & Repeat Motif & No of Alleles & Allele Size (bp) & PIC \\
\hline \multirow{2}{*}{1} & TAA45F & GCACCTTTTATACCTGACTCGG & TAA & 4 & $80-150$ & 0.65 \\
\hline & TAA45R & TTCAGCATTTGAGTTGGTTACG & & & & \\
\hline \multirow{2}{*}{2.} & TAA52F & GATCTTGACTGAACTTAAAG & TAA & - & - & - \\
\hline & TAA52R & ATGTATTGTGTTGATTACG & & & & \\
\hline \multirow{2}{*}{3.} & TAA41F & AGGTCTACATTGGCATTGTC & TAA & 4 & $50-170$ & 0.62 \\
\hline & TAA41R & ACATGCAGTGCTATAATGAAGT & & & & \\
\hline \multirow{2}{*}{4.} & TAA15F & GAAAGGGTTACTTGACCAGGC & TAA & 3 & $160-200$ & 0.51 \\
\hline & TAA15R & CTTCCCAGCTGCACAAGC & & & & \\
\hline \multirow{2}{*}{5.} & TAA3F & AGAGAAGAAACATTTGCGGAGC & TAA & 3 & $130-170$ & 0.63 \\
\hline & TAA3R & GAGATGGGACTTGGTTCACACG & & & & \\
\hline \multirow{2}{*}{6.} & CAT01F & GCTTTCGATCCCTCCACATA & CAT/ & 4 & $50-180$ & 0.75 \\
\hline & CAT01R & GATCCCTACAATCCTTGGTCC & CTT & & & \\
\hline \multirow{2}{*}{7.} & $\mathrm{CAC} 15 \mathrm{~F}$ & TAAATCTCCACTCTGCAAAAGC & CAC & 3 & $180-225$ & 0.43 \\
\hline & CAC15R & GATAGGAAGCGTCGTAGACCC & & & & \\
\hline \multirow{2}{*}{8.} & TAA27F & GGATGAAAAATGCTCAAAATG & TAA & 3 & $80-125$ & 0.62 \\
\hline & TAA27R & TAGTACCCACAGGGAAGAGAGC & & & & \\
\hline \multirow{2}{*}{9.} & CT19F & CGCCAAGCTTACCACTCACTAC & CT & 3 & $50-155$ & 0.34 \\
\hline & CT19R & GCCACGATTTGTAGGGGATAG & & & & \\
\hline \multirow{2}{*}{10.} & $\mathrm{TC} 26 \mathrm{~F}$ & CTTCCTCTTGCGGAGTGTTC & $\mathrm{TC}$ & 2 & $130-145$ & 0.49 \\
\hline & TC26R & GAGGGAAAGCCCTAATCTCA & & & & \\
\hline \multirow{2}{*}{11.} & AG14F & AAAGGGAAAGCCCTAATCTCA & GA & 2 & $125-140$ & 0.36 \\
\hline & AG14R & CTTCCTCTTGCGGAGTGTTC & & & & \\
\hline \multirow{4}{*}{12} & GT03F & GCCTTCTTGATTTACCGGAC & GT & 2 & $120-180$ & 0.18 \\
\hline & GT03R & TGCTCCGAACTTCATCATTG & & & & \\
\hline & & Total & & 33 & - & 5.41 \\
\hline & & Mean & & 3 & - & 0.50 \\
\hline
\end{tabular}




\subsection{Data Analysis}

Amplified fragment bands were scored as discrete variable " 1 " is present and " 0 " is absence. The molecular size of the PCR product was estimated by comparing the position of band with $100 \mathrm{bp}$ plus DNA ladder (Gene Ruler $^{\mathrm{TM}}$, Fermentas, Life Science). The binary data matrix obtained from the SSR profile, generated by twelve primers pair from 62 samples were analyzed using numerical taxonomy and multivariate system (NTSYS-PC, version 2.21i, Exeter software, Setauket, New York, USA). Genetic similarity was calculated by using SIMQUAL (Similarity for qualitative data) computational algorithm of Jaccards coefficient [39] methods. Based on the similarity matrix, sequential agglomerative, hierarchical and nested clustering was performing using the Unweighted Pair group method of Airthmetic Average (UPGMA) algorithm. Diversity levels of loci were evaluated by polymorphic information content (PIC value) according to the formula [40].

$$
\mathrm{PIC}=1-\sum_{j=i}^{n}\left(P_{i j}\right)^{2}
$$

where, $P_{i}$ is frequency of the $j$ th pattern for marker $i$ and the summation extends over $n$ patterns.

\section{Results}

\subsection{SSR Analysis and Genetic Diversity within Accessions}

Out of twelve SSR markers, eleven were amplified in the 62 DNA samples. Total number of alleles amplified by eleven primers pair was 33, with average 3 alleles per locus. The highest number of alleles was 4 , in TAA45, TAA41 and CAT01 loci and lowest number was 2, in TC26, AG14 and GT03 loci. The average polymorphic information content (PIC) value was 0.50 and the highest value was 0.75 and the lowest was 0.18 in CAT01 and in GT03 locus respectively (Table 2). All the alleles amplified by CAT01 primer pairs on acid lime accessions were well distinguishable (Figure 1). Double and triple bands were also amplified by the SSR primers in few accessions. Few samples that were collected from terai site is hybrid and that has been shown like double band but that may be primer dimmer or hybrid (Figure 1, plate (d)). The size of the allele amplified by the eleven primers pairs was ranged from 50 to $225 \mathrm{bp}$.

\subsection{Genetic Relationship of Acid Lime Landraces}

Data were collected based on the presence or absence of binary scoring method. The binary data set was obtained from SSR markers were used to create the correlation matrix. The matrix was used to estimate the genetic

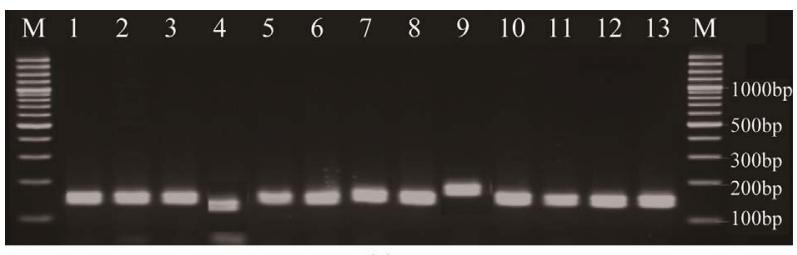

(a)

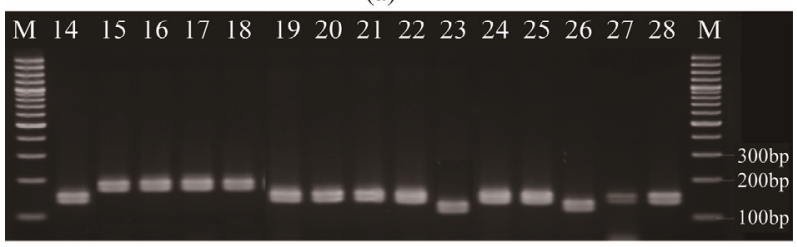

(b)

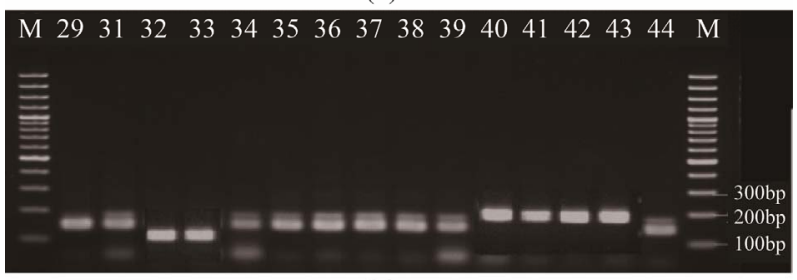

(c)

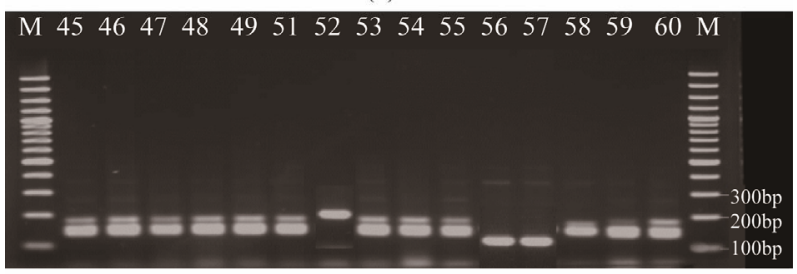

(d)

Figure 1. SSR Profile generated in 62 acid lime landraces by CAT01 primer pair (a), (b), (c), and (d). Lanes marked M are 100 bp plus molecular marker.

similarity between the acid lime accessions [41]. Based on the dendrogram and Jaccard's coefficient similarity level, genetic relationship of within the 62 acid lime accessions was observed $54 \%$. Total accessions were separated into five major cluster groups. The majority of the 39 accessions are grouped under the cluster B, whereas single accession LM-58, is in group "E". Cluster group "A" consisted of 14 accessions and group " $\mathrm{C}$ " consisted of 6 accessions, whereas cluster " $D$ " consisted of only two LM-56 and LM-57 accessions (Figure 2). There was small genetic variation between cluster group A, B and C $(75 \%, 72 \%$ and $73 \%)$, whereas group " $E$ " had wider variation (54\%). Average genetic similarity among the 62 lime accessions was $77 \%$, ranging from $54 \%$ to $100 \%$. Cluster group A, B, and C has narrower genetic relationship than "D" and "E". The result shows that, accessions LT-2 and LT-3, LT-6 and LT-8, and LT-11 and LT-12 are in the same genetic level group under the cluster "A", where as LT-15, LT-16, LT-17 and LT-18, LT-23 and LD-26, LS-34 and LM-44, LS-37 and LS-38, LD-32 and LD-33, and LS-35 and LS-39 accessions are in the same genetic level grouped under the cluster "B". The acce- 


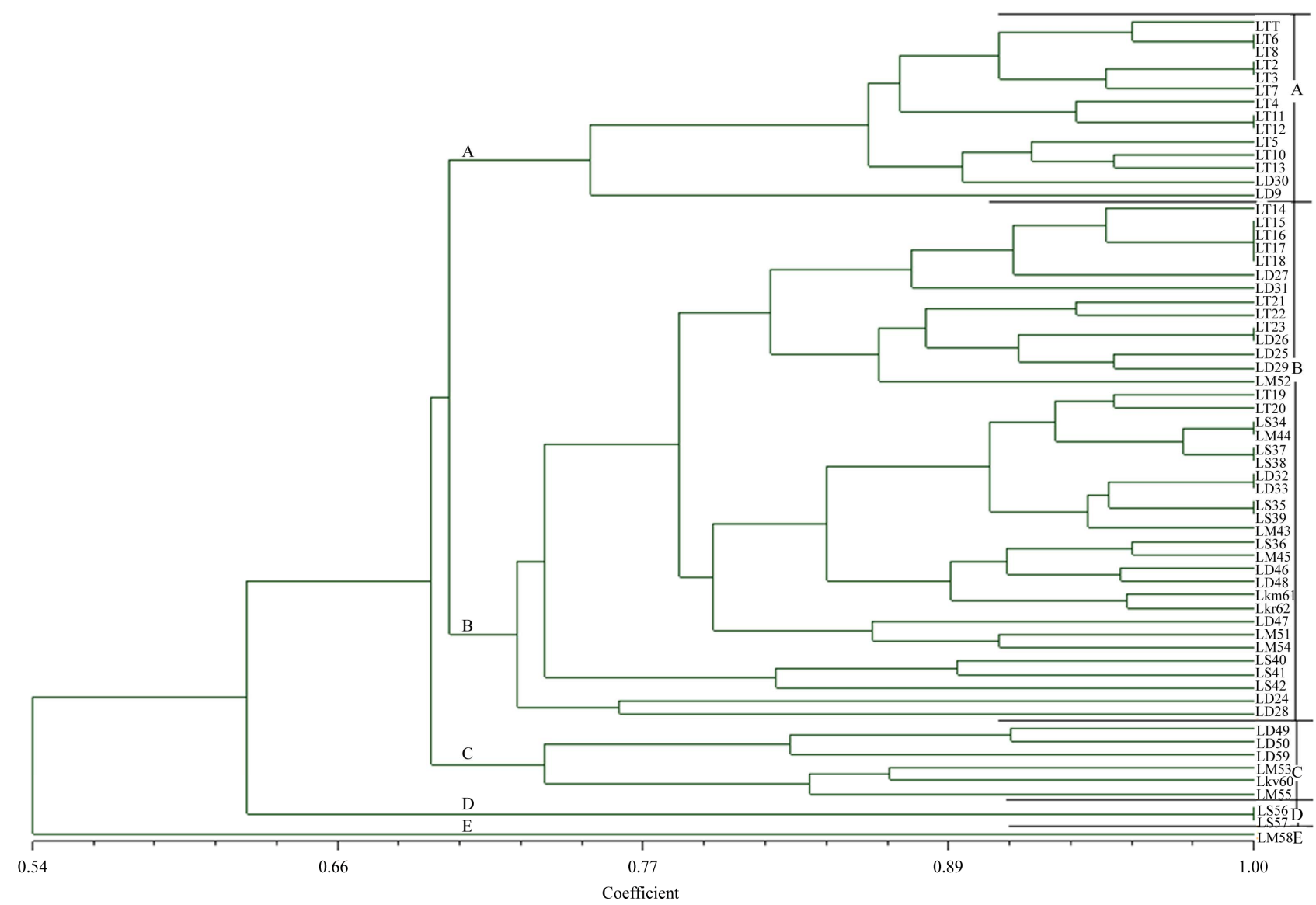

Figure 2. UPGMA (Unweighted pair group method based on arithmetic means) dendrogram derived from similarity matrix of Jaccard's coefficient, demonstrating the genetic relationships among 62 accession of acid lime landraces, based on 11 microsatellite markers.

ssions LS-56 and LS-57 are in the same genetic level in group "D" where as LM-58 has wider dissimilarity in group E (Figure 2).

\section{Discussion}

A total of twelve SSRs primer pairs were used for evaluation of genetic diversity in 62 acid lime accessions. Among them, eleven primers pairs were amplified computable bands; primer TAA52 could not amplify and escaped from scoring. The average number of alleles per locus provides complementary information of polymerphism and more adequate to co-dominant markers, because dominant markers did not permit the detection of all alleles [42]. In this study, total of 33 alleles were detected with average number of alleles per locus was 3 . The highest number of alleles was 4 and it was observed in CAT01, TAA14 and TAA47 loci and the lowest was 2 observed in TC26, AG14 and GT03 loci. Maximum of 5 alleles amplified by CAT01, and TAA14 primer pairs while a minimum of two alleles amplified by TC26 primers in Satsuma orange [43]. Average 6 alleles was observed in Mandarin and lemon accessions [44], whereas
4.4 alleles per locus was observed in the diversity of citrus species by SSR markers [45]. On the other hand, 32 alleles were amplified by 9 SSR markers on Mandarin germplasm in Brazil [46].

All the amplified alleles were polymorphic and PIC values were 0.75 in CAT01 locus, which is the best and most informative marker among the eleven SSR primers pairs. Locus CAT01 provide excellent fingerprint patterns and high polymorphism in citrus species [38]. PIC value ranging from 0 to 0.59 (Mean $=0.19$ ) in citrus and its related genera [25]. On the other hand, PIC value of SSRs primer ranges from 0.49 to $0.73($ Mean $=0.61)$ in citrus species [47]. In the Figure 1 plate " $D$ ", diploid bands was visible in the few lime accession, that may be primer dimmer or hybrids. Because, most of the samples were collected from the seeded trees and may be cross with other cultivars previously and SSR markers may distinguished the genetic characters. A set of SSRs marker detect the considerable level of genetic variability within the acid lime landraces [38].

The results shows the high level of genetic similarity within the acid lime accession. The dendrogram shows 
that 62 acid lime accessions were separated in five cluster groups. The cluster group "D" and "E" have higher level of genetic distance, because these accessions are morphologically different from other groups and were collected from the terai. In the cluster group "C" genetic similarity level was 0.73 and consisted of 6 accessions, containing thick peel higher juice percentage. In the cluster group "A", genetic similarity level was observed 0.75. In this group the fruits have thin peel and more acidic, and were collected from high and mid hills. In the cluster group "B" genetic similarity level was observed 0.73 and most of the accession are grouped under this group representing all altitude range and does not affect the environment.

High level of genetic diversity in acid lime landrace has been reported by previous studies and composed of different phenotype, genotype and large number of hybrid. This variation allows identifying the different cultivars with molecular markers. Molecular marker may provide information on the history and biology of cultivars, but it does not necessary to reflect what may be observed in morphological traits [48]. For a trait, like fruit weight and juice it is likely that there were many controlling gene spread throughout the genome. Our results proved that, the accessions collected from different altitude range were morphologically similar, but genetically distinct within the accessions, where high variation was observed in terai accession than mid and higher hills.

\section{Conclusion}

Identification of specific marker will become useful and efficient tools in the breeding program of citrus species. SSR marker proved the highly polymorphic and more informative marker within the single species of acid lime landraces. Among the tested SSR primers pairs CAT01, TAA45, TAA41, TAA15 and TAA3 had higher PIC values and were more informative for acid lime diversity analysis. It is a cross pollinated crops and large amount of genetic variation were exists within the accessions, that can be use efficiently for gene tagging and genome mapping of favorable traits such as larger fruit, high juicy, potential to disease and insect resistance into the cultivated genotype. The result of this study provides the valuable information to breeders for efficient development of new variety of acid lime.

\section{Acknowledgements}

Authors are grateful with the Vice Chancellor of NAST to access the working environment in the laboratory for molecular research. Also grateful with the molecular laboratory team of NAST for their kind cooperation and highly acknowledged to Dr. J. Bajhrachrya, Seed Science
Technology and Research Division and Dr. R. K. Niraula, Bio Technology Unit, NARI, Khumaltar for appropriate guiding and valuable suggestion.

\section{REFERENCES}

[1] Anonymous, "National Citrus Research Program," Annual Report, Paripatle, 2006.

[2] MOA, "Statistical Information of Nepalese Agriculture," Ministry of Agriculture and Cooperatives, Agri Business Promotion and Statistical Division, Singh Durbar, 2008.

[3] FAO, "Food and Agriculture Organization of the United Nations Developments in International Citrus Trade in 2004-2005," 2006.

[4] R. W. Scora, "Biochemistry, Taxonomy and Evolution of Modern Cultivated Citrus," In: R. Goren and K. Mendel, Eds., Proceedings of the International Society of Citriculture, Vol. 1, 1988, pp. 277-289.

[5] B. S. Dhillon and J. S. Randhawa, "Fruit Growth and Development in Citrus," Advance in Horticulture, Malhotra Publishing House, New Delhi, Vol. 3, 1993, pp. 1667-1683.

[6] E. Nicolosi, Z. N. Deng, A. Gentile, S. La Malfa, G. Continella and E. Tribulato, "Citrus Phylogeny and Genetic Origin of Important Species as Investigated by Molecular Markers," Theoretical and Applied Genetics, Vol. 100, No. 8, 2000, pp. 1155-1166. doi:10.1007/s001220051419

[7] R. W. Scora, "On the History and Origin of Citrus," Bulletin of the Torrey Botanical Club, Vol. 102, No. 6, 1975, pp. 369-375. doi:10.2307/2484763

[8] H. C. Barrett and A. M. Rhodes, "A Numerical Taxonomic Study of the Affinity Relationships in Cultivated Citrus and Its Close Relatives," Systematic Botany, Vol. 1, 1976, pp. 105-136. doi:10.2307/2418763

[9] S. K., Verma, "A Brief Introduction to Horticulture Development Project," Horticulture Development Follow Up Program, Kirtipur, 1999.

[10] H. D. Upadhya, S. L. Dwivedi, C. L. L. Gowda and S. Singh, "Identification of Diverse Germplasm Line for Agronomic Traits in Chickpea (Cicer arietinum L.) Core Collection for Use in Crop Improvement," Field Crops Research, Vol. 100, No. 2-3, 2007, pp. 230-236. doi:10.1016/j.fcr.2006.08.008

[11] J. Ni, P. M. Colowit and D. J. Mackill, "Evaluation of Genetic Diversity in Rice Sub Species Using Microsatellite Markers," Crop Science, Vol. 42, No. 2, 2002, pp. 601-607. doi:10.2135/cropsci2002.0601

[12] D. Q. Fang, M. L. Roose, R. R. Krueger and C. T. Federici, "Fingerprinting Trifoliate Orange Germplasm Accessions with Isozymes, RFLPs, and Inter-Simple Sequence Repeat Markers," Theoretical and Applied Genetics, Vol. 95, 1997, pp. 211-219. doi: $10.1007 / \mathrm{s} 001220050550$

[13] H. D. C. Filho, M. A. Machado, M. L. P. N. Targon, M. C. P. Q. D. G. Moreira and J. Pompeu, "Analysis of the Genetic Diversity among Mandarins (Citrus spp.) Using RAPD Markers," Euphytica, Vol. 102, No. 1, 1998, pp. 133-139. doi:10.1023/A:1018300900275 
[14] V. M. Novelli, M. A. Machado and C. R. Lopes, "Isoenzymatic Polymorphism in Citrus spp. and P. trifoliata (L.) Raf. (Rutaceae)," Genetics and Molecular Biology, Vol. 23, 2000, pp. 163-168. doi:10.1590/S1415-47572000000100030

[15] J. M. H. Kijas, M. R. Thomas, J. C. S. Fowler and M. L. Roose, "Integration of Trinucleotide Microsatellites into a Linkage Map of Citrus," Theoretical and Applied Genetics, Vol. 94, 1997, pp. 701-706. doi: $10.1007 / \mathrm{s} 001220050468$

[16] A. A. Sanker and G. A. Moore, "Evaluation of InterSimple Sequence Repeat Analysis for Mapping in Citrus and Extension of the Genetic Linkage Map," Theoretical and Applied Genetics, Vol. 102, No. 2, 2001, pp. 206-214. doi:10.1007/s001220051637

[17] J. M. H. Kijas, J. C. S. Fowler and M. R. Thomas, “An Evaluation of Sequence Tagged Microsatellite Site Markers for Genetic Analysis within Citrus and Related Species," Genome, Vol. 38, No. 2, 1995, pp. 349-355. doi:10.1139/g95-045

[18] R. Herrero, M. J. Asins, E. A. Carbonell and L. Navarro, "Genetic Diversity in the Orange Subfamily Aurantioideae. I. Intraspecies and Intragenus Genetic Variability," Theoretical and Applied Genetics, Vol. 92, No. 5, 1996, pp. 599-609. doi:10.1007/BF00224564

[19] S. M., Brown, M. S. Hopkins, S. E. Mitchell, M. L. Senior, T. Y. Wang, R. R. Duncan, F. Gonzalez-Candelas and S. Kresovich, "Multiple Methods for the Identity Wcation of Polymorphic Simple Sequence Repeats (SSRs) in Sorghum (Sorghum spp.)," Theoretical and Applied Genetics, Vol. 93, 1996, pp. 190-198. doi:10.1007/BF00225745

[20] S. C. Hokanson, A. K. Szewc-McFadden, W. F. Lamboy and J. R. McFerson, "Microsatellite (SSR) Markers Reveal Genetic Identities, Genetic Diversity and Relationships in a Malus $£$ domestica Borkh," Core Subset Collection, Theoretical and Applied Genetics, Vol. 97, No. 5, 998, pp. 671-683.

[21] K. Liu, M. Goodman, S. Muse, J. S. Smith E. Buckler and J. Doebley, "Genetic Structure and Diversity among Maize Inbred Lines as Inferred from DNA Microsatellites," Genetics, Vol. 165, No. 4, 2003, pp. 2117-2128.

[22] P. K. Gupta, H. S. Balyan, P. C. Sharma and B. Ramesh, "Microsatellites in Plants: A New Class of Molecular Markers," Current Science, Vol. 70, No. 1, 1996, pp. 4554.

[23] D. Tautz, "Hypervariability of Simple Sequences as a General Source of Polymorphic DNA Markers," Nucleic Acids Research, Vol. 17, 1989, pp. 6463-6471. doi:10.1093/nar/17.16.6463

[24] B. Golein, A. Talaie, Z. Zamani, A. Ebadiand and A. Behjatnia, "Assessment of Genetic Variability in Some Iranian Sweet Oranges (Citrus sinensis [L.] Osbeck) and Mandarins (Citrus reticulata Blanco) Using SSR markers," International Journal of Agriculture and Biology, Vol. 7, No. 2, 2005, pp. 167-170.

[25] K. Weising and R. C. Gardner, "A Set of Conserved PCR Primers for the Analysis of Simple Sequence Repeat Polymorphism in Chloroplast Genomes of Dicotyledo- nous Angiosperm," Genome, Vol. 42, No. 1, 1999, pp. 919. doi:10.1139/g98-104

[26] M. J. C. Nunes, M. A. Machado, W. M. C. Nunes, M. Cristofania and M. L. P. N. Targon, "Assessment of Genetic Variability in Grapefruits (Citrusparadisi Macf.) and Pummelos (C. maxima (Burn.) Merr.) Using RAPD and SSR Markers," Euphytica, Vol. 126, 2000, pp. 169-176. doi:10.1023/A:1016332030738

[27] P. Guilford, S. Parkash, J. M. Zhu, E. Rikkerink, S. Gardiner, H. Bassett and R. Forster, "Microsatellite in Apple (Malus domestica), Abundance, Polymorphism and Cultivar Identification," Theoretical and Applied Genetics, Vol. 94, No. 2, 1997, pp. 245-249. doi:10.1007/s001220050407

[28] M. R. Thomas and N. S. Scott, "Microsatellite Repeats in Grapevine Reveal DNA Polymorphism When Analysed as Sequence-Tagged Sites (STSs)," Theoretical and Applied Genetics, Vol. 86, 1993, pp. 985-990. doi:10.1007/BF00211051

[29] C. He, V. Poysa and K. Yu, "Development and Characterization of Simple Sequence Repeat (SSR) Markers and Their Use in Determining Relationships among Lycopersicon esculentum Cultivars," Theoretical and Applied Genetics, Vol. 106, 2003, pp. 363-373.

[30] G. He, R. Meng, M. Newman, G. Gao, R. N. Pittman and C. S. Prakash, "Microsatellites as DNA Markers in Cultivated Peanut (Arachis hypogaea L.)," BMC Plant Biology, Vol. 3, No. 1, 2003, pp. 1-6. doi:10.1186/1471-2229-3-3

[31] M. Rossetto, A. Mclauchlan, F. C. L. Harriss, R. J. Henry, P. R. Baverstock, L. S. Lee, T. L. Maguire and K. J. Edwards, "Abundance and Polymorphism of Microsatellite Markers in the Tea Tree (Melaleuca alternifolia, Myrtaceae)," Theoretical and Applied Genetics, Vol. 98, No. 6, 1999, pp. 1091-1098. doi:10.1007/s001220051172

[32] M. A. Viruel and J. I. Hormaza, "Development, Characterization and Variability Analysis of Microssatellites in Lychee (Litchi chinensis Sonn, Sapindaceae)," Theoretical Applied Genetics, Vol. 108, 2004, pp. 896-902. doi:10.1007/s00122-003-1497-4

[33] X. Pang, C. Hu and X. Deng, "Phylogenetic Relationships among Citrus and Its Relatives as Revealed by SSR Markers," Acta Genetica Sinica, Vol. 30, No. 1, 2003, pp. 81-87.

[34] P. Koehler-Santos, A. L. Dornelles and L. B. Freitas, "Characterization of Mandarin Citrus Germplasm from Southern Brazil by Morphological and Molecular Analyses," Pesquisa Agropecuária Brasileira, Vol. 38, No. 7, 2003, pp. 797-806. doi:10.1590/S0100-204X2003000700003

[35] C. Ruiz, M. P. Breto and M. J. Asins, "A Quick Methodology to Identify Sexual Seedlings in Citrus Breeding Programs Using SSR Markers," Euphytica, Vol. 112, No. 1, 2000, pp. 89-94. doi:10.1023/A:1003992719598

[36] N. A. Barkley, M. L. Roose, R. R. Krueger and C. T. Federici, "Assessing Genetic Diversity and Population Structure in a Citrus Germplasm Collection Utilizing Simple Sequence Repeat Markers (SSRs)," Theoretical and Applied Genetics, Vol. 112, No. 8, 2006, pp. 1519- 
1531. doi:10.1007/s00122-006-0255-9

[37] B. Golein, A. Talaie, Z. Zamani and B. Moradi, "Development and Characterization of New Microsatellite Loci from Lemon (Citrus lemon)," International Journal of Agriculture and Biology, Vol. 8, No. 2, 2006, pp. 172174.

[38] M., R. Jannati, A. Fotouhi, P. Abad and Z. Salehi, "Genetic Diversity Analysis of Iranian Citrus Varieties Using Micro Satellite (SSR) Based Markers," Journal of Horticulture and Forestry, Vol. 1, No. 7, 2009, pp. 120-125.

[39] F. J. Rohlf, "NTSYS-PC Numerical Taxonomy and Multivariate Analysis System," Version 1.80. Exeter Software, Setauket, New York, 1993.

[40] M. Nei, "Genetic Distance between Populations," American Naturalist, Vol. 106, No. 949, 1973, pp. 283-292. doi: $10.1086 / 282771$

[41] M. Nei and W. H. Li, "Mathematical Models for Studying Genetic Variation in Terms of Restriction Endonucleases," Proceedings of the National Academy of Sciences, Vol. 76, 1979, pp. 5269-5273. doi:10.1073/pnas.76.10.5269

[42] IPGRI, "Isolated from a Size-Fractionated Genomic Library of Brassica napus L. (rapeseed)," Theoretical and Applied Genetics, Vol. 91, 1999, pp. 206-211.

[43] A. Ghanbari, N. B. Jelodar and H. Rahiman, "Studying of Genetic Diversity in Satsuma (Citrus unshiu) Mandarin utilizing Microsatellite Markers," International Journal of Agricultural Research, Vol. 4, 2009, pp. 88-96. doi:10.3923/ijar.2009.88.96

[44] Y. Z. Li, Y. J. Cheng, H. L. Yi and X. X. Deng, "Genetic Diversity in Mandarin Landraces and Wild Mandarins from China Based on Nuclear and Chloroplast Simple Sequence Repeat Markers," Journal of Horticultural Science and Biotechnology, Vol. 81, No. 3, 2006, pp. 371378.

[45] P. K. Santos, A. L. C. Dornelles and L. B. Freitas, "Characterization of Mandarin Citrus Germplasm from Southern Brazil by Morphological and Molecular Analyses," Pesquisa Agropecuária Brasileira, Vol. 38, No. 7, 2003, pp. 797-806. doi:10.1590/S0100-204X2003000700003

[46] Q.-Q. Cao, H.-J. Meng, X.-P. Wen, H.-L. Yi and X.-X. Deng, "Genetic Diversity of Male Sterile and Low Fertility Germplasm of Citrus Revealed Using SSR Markers," Chinese Journal of Agricultural Biotechnology, Vol. 4, No. 2, 2007, pp. 99-104. doi:10.1017/S1479236207001453

[47] G. J. Bryan, J. McNicoll, G. Ramsay, R. C. Meyar and W. S. D. Jong, "Polymorphic Simple Sequence Repeatmarker in Chloroplast Genome of Solanaceious Plant," Theoretical and Applied Genetics, Vol. 99, No. 5, 1999, pp. 859867. doi:10.1007/s001220051306

[48] I. Metais, C. Aubry, B. Hamon and R. Jalouzot, "Description and Analysis of Genetic Diversity between Commercial Bean Lines (Phaseolus vulgaris L.)," Theoretical and Applied Genetics, Vol. 101, No. 8, 2000, pp. 1207-1214. doi:10.1007/s001220051599 